\title{
lleal tuberculosis presenting as a case of massive rectal bleeding
}

This article was published in the following Dove Press journal:

Clinical and Experimental Gastroenterology

I8 November 2009

Number of times this article has been viewed

Manoj Kela

Ashish Agrawal

Rajesh Sharma

Rajeev Agarwal

Vinita B Agarwal

Department of Surgery, S.A.I.M.S.

Medical College, Indore,

Madhya Pradesh, India
Correspondence: Manoj Kela Department of Surgery, S.A.I.M.S. Medical

College, Indore, Madhya Pradesh, India 452001

Tel +9l 9303230585

Emaildrmpkela@yahoo.com
Abstract: Massive rectal bleeding is an uncommon presentation of ileal tuberculosis. Fewer than 12 cases are reported in the literature. We report a case of ileal tuberculosis presenting at the emergency department with subacute intestinal obstruction and severe rectal bleeding. The case of the massive bleeding could be identified only after an exploratory laparotomy.

Keywords: massive rectal bleeding, ileum, intestinal tuberculosis

\section{Introduction}

The clinical manifestations of intestinal tuberculosis are nonspecific. Most patients present with low grade fever, weight loss, abdominal pain, anorexia, or diarrhea. ${ }^{1}$ Ileal tuberculosis is one of the commonly encountered surgical emergencies; the incidence of intestinal tuberculosis in presence of active pulmonary tuberculosis is between $3 \%-90 \%$. 2,3 Varied acute presentations of ileal tuberculosis are encountered such as subacute intestinal obstruction due to stricture or adhesions, or tuberculous stricture perforation. Massive rectal bleeding is considered a rarely presented symptom of intestinal tuberculosis. ${ }^{4-9}$ The ileocaecal region is the most common site of gastrointestinal involvement and hemorrhage due to tuberculosis is often occurred in this region. ${ }^{6}$ Here we report an Indian male diagnosed with ileal tuberculosis presenting with massive bleeding from the rectum.

\section{Case report}

A 30-year-old male patient presented to us with a complaint of being unable to evacuate his bowels and flatulence for the previous two days and with persistant bleeding from the rectum for one day. No other positive history was elicited. On examination, patient was pale. He had a pulse rate of 120 beats/minute and blood pressure was $90 / 60 \mathrm{~mm} \mathrm{Hg}$. Rectal examination showed the presence of fresh blood. Ryle's tube showed the presence of clear bile. Patient was stabilized haemodynamically. Upper gastrointestinal endoscopy performed was normal. Emergency investigations showed $\mathrm{Hb}$ of $4 \mathrm{~g} \%$ and hematocrit $29 \%$. The white blood cell count was $1,800 / \mu$ l and platelet count was $95,000 / \mu 1$. Chest X-ray was found to be normal. Patient's rectal bleeding continued, hence a colonoscopy was performed, which could not be completed since the whole colon was filled with blood and blood clots. Hence a decision to explore the patient in view of persistent rectal bleeding was undertaken after adequate blood transfusion. At laparotomy terminal ileum was full of blood and a nonpassable stricture was seen in the terminal ileum one and a half feet from the ileocaecal junction and mesenteric 
lymph nodes were also enlarged. The rest of the bowel was unremarkable. A resection anastomosis of the stricture was performed. After opening the lumen of ileum which was resected, longitudinally we found polypoidal mass of size $3.5 \times 2.5 \times 2 \mathrm{~cm}$ intraluminally adjoining the stricture having hemorrhagic surface area. Rest of mucosa shows multiple superficial ulcers of size $0.5 \mathrm{~cm}$ (Figure 1). Histopathology showed the presence of epitheloid granulomas and Langhanstype giant cells and evidence of endarteritis, suggestive of tuberculous etiology (Figure 2) Patient was started on four anti-tubercular drugs, and had an uneventful post-operative recovery.

\section{Discussion}

Intestinal tuberculosis is much more difficult to diagnose than pulmonary tuberculosis and requires a high index of suspicion. Intestinal tuberculosis presenting with lower gastrointestinal bleed is rare and accounts for about $5 \%$ of cases of lower gastrointestinal bleeding. ${ }^{2,3}$ In the presence of active pulmonary tuberculosis, vague abdominal pain, weight loss, and passage of a small amount of blood from the rectum could suggest the possibility of intestinal tuberculosis., ${ }^{2,6}$

Colonoscopy followed by biopsy is considered the most effective investigation for definitive diagnosis of ileocaecal and colonic tuberculosis. ${ }^{10}$ However, the endoscopic and histological examination of the involved areas often shows nonspecific findings and cultures for tuberculosis are often negative. ${ }^{11}$

The patient had no evidence of active pulmonary tuberculosis and had massive rectal bleeding so exploratory laprotomy was performed and ileal tuberculosis was diagnosed on the basis of histopathological examinations. Pathologic findings of a short diseased segment of ileum is common, although it is unusual to have proximal ileum involvement without the involvement of terminal ileum; the patient had a solitary stricture in the terminal ileum. The granulomas in the bowel may be noncaseating with circumferential ulcers, which can lead to bowel obstruction. ${ }^{2-4}$ Massive gastrointestinal bleed occurs because of underlying obliterative endarteritis within the ulcer cater. ${ }^{2}$ The patient had both stricture formation and evidence of obliterative endarteritis. Technetium 99m-labeled red blood cell scan can help localize the bleeding lesion. ${ }^{3}$

In a literature review, we found only 10 cases of intestinal tuberculosis presenting with bleeding per rectum. ${ }^{2-5,7-9,12-14}$ Of these patients, seven had bleeding from the ileocaecal area, ${ }^{2,4-6,13-15}$ two from the descending colon, ${ }^{16,17}$ and one from the transverse colon. ${ }^{18}$ Thus, in most of these patients, the bleeding occurred from the ileocecal area and massive

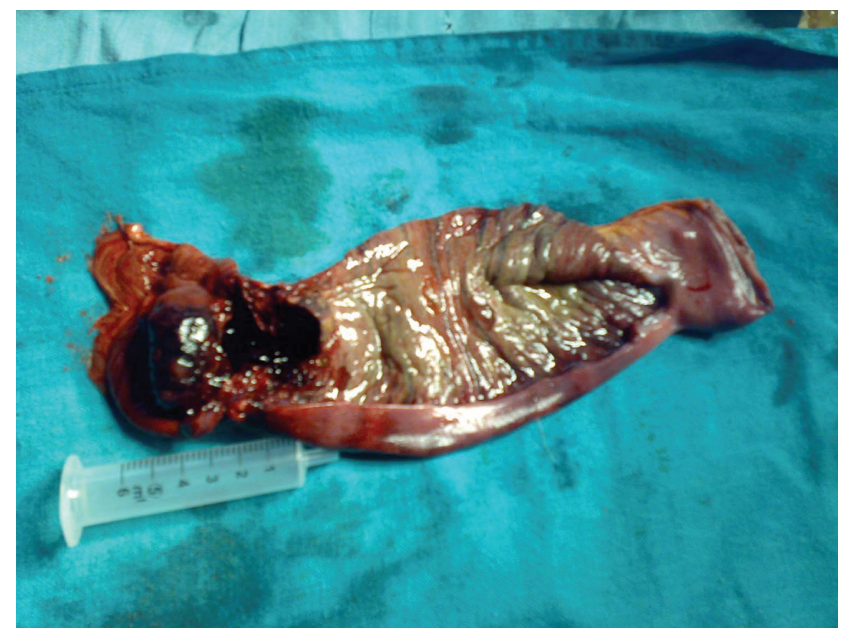

Figure I Resected specimen of ileum showing polypoidal mass of size $3.5 \times 2.5 \times 2$ $\mathrm{cm}$ intraluminally adjoining the stricture having hemorrhagic surface area and rest of the mucosa shows multiple superficial ulcers of $0.5 \mathrm{~cm}$ size.

bleeding from ileum or jejunum (except for terminal ileum) was not reported.

In a study of 130 patients with alimentary tract tuberculosis by $\mathrm{Al}$ Karawi and colleagues, ${ }^{1}$ the disease was located in the small bowel in 44 patients $(33.8 \%)$ and in the large bowel in 29 patients $(22.3 \%)$. Moreover, in their study of 44 patients with small bowel tuberculosis, hemorrhage was observed in only one patient but was observed in three of 29 patients with large bowel tuberculosis. ${ }^{1}$ According to their report, it is suggested that bleeding from small bowel tuberculosis is rare although small bowel tuberculosis is not so uncommon.

Barium enema was performed in seven of 10 patients who reported with intestinal tuberculosis with massive rectal bleeding. Colonic lesions were revealed in five

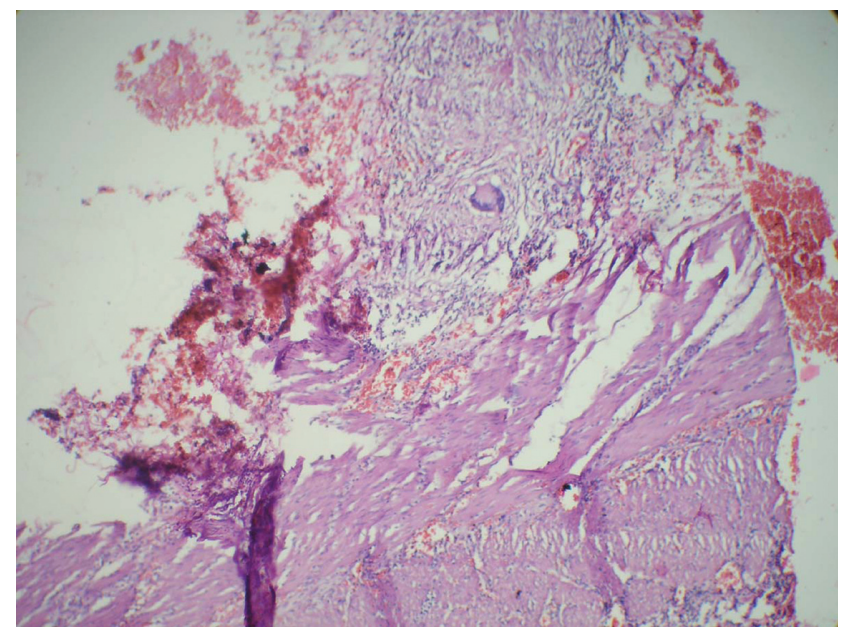

Figure 2 Histopathology slide showing the presence of epitheloid granulomas and Langhans-type giant cells and evidence of endarteritis, which is suggestive of tuberculous etiology. 
patients. The nature of the lesions remained unrecognized preoperatively. Carcinoma or Crohn's disease were the most common preoperative diagnoses.

Colonoscopy was performed in four of 10 patients and showed lesions in two patients. Except for one patient, ${ }^{16}$ histological small intestinal tuberculosis was not found. $99 \mathrm{mTc}$ red blood cell scintigraphy was useful to locate the bleeding lesion and to make a preoperative diagnosis of hemorrhage from the ileum. 99Tc red blood cell scintigraphy is more sensitive than angiography for detecting bleeding sites and can detect sites with a minimum bleeding rate as low as $0.1 \mathrm{ml} / \mathrm{min}^{19}$

Our literature review found that the preferred treatment of intestinal tuberculosis was medical. Except for one patient with bleeding from the descending colon, ${ }^{16}$ patients with massive bleeding from intestinal tuberculosis were treated by laprotomy and antitubercular drugs postoperatively. Histological examination of resected specimen showed caseating granulomas in all patients. This finding indicates that surgery remains the definitive therapeutic for the diagnosis and treatment of patients of massive rectal bleeding due to intestinal tuberculosis. Indeed, in our patient, no rectal bleeding was seen after surgery and diagnosis was made on basis of histopathological examination of the resected specimen.

Since the symptoms associated with intestinal tuberculosis are highly variable, hemorrhage, obstruction, perforation, or fistula may occur at various levels of the small and large bowel. From our experience and review of literature, although massive rectal bleeding from intestinal tuberculosis is rare, it is suggested that small intestinal tuberculosis should be kept in mind as a cause of rectal bleeding, especially if the patient is an immunocompromised host.

\section{Conclusion}

Massive rectal bleeding is an uncommon presentation of ileal tuberculosis. In the presence of active pulmonary tuberculosis, intestinal tuberculosis can be considered as a differential diagnosis of massive rectal bleeding, especially in endemic areas of tuberculosis.

\section{Disclosures}

The authors report no conflicts of interest in this work.

\section{References}

1. Al Karawi MA, Mohamed AE, Yasawy MI, et al. Protean manifestation of gastrointestinal tuberculosis: report on 130 patients. J Clin Gastroenterol. 1995;20(3):225-232.

2. Sherman HI, Johnson R, Brock T. Massive gastrointestinal bleeding from tuberculosis of small intestine. Am J Gastroenterol. 1978;70(3):314-316.

3. Watanabe T, Kudo M, Kayaba M, et al. Massive rectal bleeding due to ileal tuberculosis. J Gastroenterol. 1999;34(4):525-529.

4. Verma P, Kapur BM. Massive rectal bleeding due to intestinal tuberculosis. Am J Gastroenterol. 1979;71(2):217-219.

5. Goudarzi HA, Mason LB. Fatal rectal bleeding due to tuberculosis of the cecum. JAMA. 1982;247(5):667-668.

6. Anscombe AR, Keddie NC, Schofield PF. Caecal tuberculosis. Gut. 1967;8(4):337-343.

7. Rabkin DG, Caiati JM, Allendorf JA, Treat M. Intractable hematochezia: an unusual presentation of intestinal tuberculosis. Surgery. 2003;133(5):592-593.

8. Park JK, Lee SH, Kim SG, et al. A case of intestinal tuberculosis presenting massive hematochezia controlled by endoscopic coagulation therapy. Korean J Gastroenterol. 2005;45(1):60-63.

9. Ndububa DA, Olasode BJ, Olatunde LO. Abdominal tuberculosis with fatal gastro-intestinal haemorrhage. Cent Afr J Med. 1997;43(6): $175-177$.

10. Marshall JB. Tuberculosis of the gastrointestinal tract and peritoneum. Am J Gastroenterol. 1993;88(7):989-999.

11. Morgante PE, Gandara MA, Sterle E. The endoscopic diagnosis of colonic tuberculosis. Gastrointest Endosc. 1989;35(2):115-118.

12. Joshi MA, Balsarkar D, Abhyankar A, et al. Massive rectal bleeding due to jejunal and colonic tuberculosis. Trop Gastroenterol. 1998;19(4):168-170.

13. Pozniak AL, Dalton-Clark HJ, Ralphs DN. Colonic tuberculosis presenting with massive rectal bleeding. Tubercle. 1985;66(4):295-299.

14. Hiran S, Pande TK, Kumar S, et al. Massive rectal bleeding due to ileocaecal tuberculosis (conservative approach). Postgrad Med J. 1994;70(819):55-56.

15. Brenner SM, Annes G, Parker JG. Tuberculous colitis simulating non specific granulomatous disease of the colon. Am J Dig Dis. 1970; 15:85-92.

16. Monkemuller KE, Lewis JB Jr. Massive rectal bleeding from colonic tuberculosis. Am J Gastroenterol. 1996;91(7):1439-1441.

17. Devanesan JD, Sable RA, Pitchumoni CS, Lev R, Zapiach L. Segmental tuberculosis of the colon mimicking carcinoma. Arch Surg. 1980;115(1):90-91.

18. Tishler JM. Tuberculosis of the transverse colon. AJR Am J Roentgenol. 1979;133(2):229-232.

19. Smith R, Copely DJ, Bolen FH. 99mTc RBC scintigraphy: correlation of gastrointestinal bleeding rates with scintigraphic findings. AJR Am J Roentgenol. 1987;148(5):869-874.
Clinical and Experimental Gastroenterology

\section{Publish your work in this journal}

Clinical and Experimental Gastroenterology is an international, peerreviewed, open access journal, publishing all aspects of gastroenterology in the clinic and laboratory, including: Pathology, pathophysiology of gastrointestinal disease; Investigation and treatment of gastointes tinal disease; Pharmacology of drugs used in the alimentary tract;

\section{Dovepress}

Immunology/genetics/genomics related to gastrointestinal disease. This journal is indexed on CAS. The manuscript management system is completely online and includes a very quick and fair peer-review system. Visit http://www.dovepress.com/testimonials.php to read real quotes from published authors. 